\title{
An Assessment of Genetic Variability in Contrasting Castor Seedlings
}

\author{
G. I. Ilo, I. A. Nweke, and S. I. Ijearu
}

\begin{abstract}
Nine genotypes of castor oil bean (Ricinus cumunis) were evaluated in 2011 and 2012 cropping seasons to determine their consistency of performance at the Enugu State University of Science and Technology, Enugu State. Eight (8) accessions were selected from various locations in the south east, while a standard check was obtained from Ahmadu Bello University Zaria. The study was carried out using a randomized complete block design with four replications. Data was collected on number of days to germination, days to $50 \%$ flowering, plant height at maturity, length of primary raceme, length of pistillate region, length of staminate region and number of leaves. The findings from the study showed that Zaria accession flowers within 80 days and significantly $(P<0.05)$ different from the other eight $(8)$ accessions studied, except Udi for plant height at maturity the significant and comparable large genotypes for all the characters except number of days to germination; number of nodes and length of staminate region implies that there would be adequate gains in selecting the characters. The phenotypic coefficient of variation was found to be higher than the genotypic coefficient of variance for all the character studied indicating the influence of environment towards the total variance. The short height recorded in Zaria and Udi accessions which are at par is of a desirable trait for shorter plants are easier to manage agronomical and it also withstands lodging better than all plants. These accessions based on the agronomic characters studied were found to perform very well in Enugu south-east, Nigeria and is therefore, recommended to be grown in this region.
\end{abstract}

Index Terms - Accessions, heritability, genetic variability, pistillate, staminate, raceme.

\section{INTRODUCTION}

Castor oil bean plant (Ricinus comnunis) is an indeterminate oil seed crop grown in draught regions like tropics and semi-arid tropics. The seed of which contains between $40 \%$ and $60 \%$ oil that is rich in triglycerides and ricinolein [1]. The castor oil plant varies greatly in its growth habit and appearance. The variability has been increased by breeders who have selected a range of cultivars for leaf and flower colours and for oil production. The leaves of some varieties are green practically from the start whereas in yet others a pigment masks the green colour of all the chlorophyll bearing parts, leaves, stems and young fruits so that they remain a dramatic purple to reddish brown throughout the life of the plant. So, in a population where dark leaves plants are found growing next to those

Published on December 19, 2020.

G. I. Ilo, Department of Crop Science, University of Nigeria, Nigeria.

I. A. Nweke, Department of Soil Science, Chukwuemeka Odumegwu Ojukwu University, Nigeria.

(e-mail: nwekson@ ${ }^{\text {hotmail.com) }}$

S. I. Ijearu, Department of Agricultural Technology, Akanu Ibiam Federal Polytechnic, Nigeria. with green leaves only indicated that single gene control the production of the pigment in some varieties.

Several agronomic characters in castor affects yield in the positive or in the negative direction such agronomic traits as the plant height, branching pattern, raceme length, flowering pattern etc influenced seen yield. The inherent ability within and among most cultivated plant species to adapt to different a biotic and biotic changes and to the changing crop management practices has enhanced their spread to the different parts of the world other than their centre of origin. According to Moreno-Gonzalez and Cubero [2] adapted plant materials are those crop plants that can be immediately cultivated in the region or area from which their improvement programme was designed. The longer a crop is able to grow in a particular site in a season, the greater is its biomass production in that site. This increase in biomass production with longer duration of growth reflects not only the opportunity for more prolonged interception of photo synthetically active radiation by the crop but also the greater opportunity for uptake of $\mathrm{N}$ and other nutrients especially under low input conditions $[3,4]$. Crop performance to locations other than their centre of diversification and domestication involves a substantial shift in the processes controlling the length and timing of their reproductive and storage cycles. Plant breeders are faced with the demand for crop varieties better adapted to changing conditions with an option either to select for closely defined ecological conditions or for more extensive conditions which include a considerable range of environments [5] clearly the latter approach requires the development of varieties possessing general adaptability since even in a uniform edaphic environment a considerable degree of general adaptability will be important because of the marked fluctuation of climatic conditions from season to season. Before a crop plant is selected desirable and adapted accessions should be evaluated in different environments. Thus, genetic manipulation of existing crop landraces, their evaluation within and across cropping systems and for environments and consequently, selection of ideal types for specific systems are important avenues for improving production in the tropics. According to Baiyeri [6], the key objective in avoiding yield decline and or sustenance of stable yield is to promote vigorous growth and / or to eliminate those factors causing poor growth and development. Such non-genetic factors that could influence growth and development especially as they relate to castor production in the sub-Sahara Africa include nutrients, moisture, light, and temperature. Evaluation studies are designed so that selections are made within targets regions to minimize the consequence of genotype by environment (GXE) variability in terms of rainfall amount, soil characteristics, solar radiation, and temperature in the targeted selection regions. Traits for selection may among 
and within genomes levels constitute a limitation on selection. Therefore, selections are made based on the trails adapted and within the different environment and those that adaptable are linked and tried in another environment. According to Obi [7] these breeding materials are evaluated as to their stability and adaptability in the various environments intended for its production and one of the ways of evaluating materials for release is genotype by environment (GXE) interaction analysis. Such environments as plant population, fertilizer requirements, sowing-dates, years, and location are sufficient to estimate the adaptability of the new variety as to the limit of the areas and other conditions suited for its optimum production. Consequence of existence of GXE interaction is that it may cause selection mode in one environment, and/ or year to poorly perform another environment of year, thus measuring GXE interaction is important to determine maximum breeding strategy for releasing accessions with adequate adaptation to the target environment; integration of stability of performance with yield according to Kang and Pham, [8] is necessary for selecting high yielding stable accessions. When the stability of performance and yield are simultaneously considered, it tends to reduce the effect of GXE interaction and make selection more precise and refined. Castor has great potential for growth in Nigerian soils as reported by Nweke, [9]. The country and south-east in particular will gain a lot from its production. Great improvement in this wonderful drought resistant crop can be achieved through breeding considering its wide genetic background. Hence the objective of this research is to assess the genetic variability in agronomic parameters of castor seed lines with a view to improve the quality performance and yield of the crop in the agro-ecological zone of south east, Nigeria.

\section{MATERIAL AND METHODS}

The study was carried out at the Department of Agronomy and Ecological Management Experimental Farm Faculty of Agriculture, Enugu State University of Science and Technology Enugu. The meteorological data used in the study such as relative humidity, ambient temperature, rainfall, solar radiation, wind velocity and soil fertility status were collected from the Department of Geography Faculty of Natural Science, Enugu State University of Science and Technology Enugu.

\section{Field PREPARATION, Planting AND CUltural PRACTICES}

The experimental field was cleared, and debris removed. Plot size measuring $300 \mathrm{~m}^{2}$ was prepared and used for the planting. Nine (9) accessions of castor to be evaluated for high yield and adaptation were obtained from various parts of Enugu State and standard check obtained from the germplasm of the Ahmadu Bello University, Zaria. Three seeds of these accessions were planted per hill and were later thinned down to one seedling per hill. Plant spacing of $1 \mathrm{~m} \times 1 \mathrm{~m}$ was used for the study. The experimental field was layered out in randomized complete block design (RCBD) with four replications. Weeding was carried out as and when due with the aid of traditional African hand hoe. Thinning and supplying were done simultaneously one week (7days) after planting. The same procedures were observed for the two years planting seasons (2011 and 2012 cropping seasons).

\section{DATA COLLECTION}

Data were collected from the following parameters, days to germination; days to $50 \%$ flowering; Plant height; length of primary raceme; length of staminate region, number of leaves.

The estimates of broad sense heritability $\left(\mathrm{H}^{2}\right)$ were calculated using the formula of Burton [10] and Johnson et al. [11].

$$
H^{2}=\frac{\delta^{2} g}{\delta^{2} g+\delta^{2} e}
$$

where $H^{2}=$ Heritability.

$\delta^{2} g=$ Genotypic variance.

$\delta^{2} e=$ Environmental variance.

Phenotypic and genotypic co-efficient of variance in percentage was estimated using the formula of Burton and Devane [12].

$$
\begin{aligned}
& \text { P.C.V. }(\%)=\frac{\delta^{2} p h}{X 1} \times 100 \\
& \text { G.C.V. }(\%)=\frac{\delta^{2} g}{X 1} \times 100
\end{aligned}
$$

where $\delta^{2} p h=$ Phenotypic variance.

$X=$ Sample mean of each trait.

The difference between the phenotypic and environmental variance were used to estimate the accessions variance.

The data collected from the study were subjected to the analysis of variance (ANOVA) as outlined for the design using Gensat 3.0 release [13] to test for differences in the treatments, while mean separation was done using least significant difference as outlined by Obi [14].

\section{RESULTS}

A. Number of Days to Germination for Each of the Castor Accessions Studied

The number of days to germination result of castor accessions presented in Table 1 showed that in 2011 cropping seasons, Enugu and Agbani accessions recorded the highest (12.25) number of days to germination of which was significantly $(\mathrm{P}<0.05)$ different from Igboeze and Eke accessions that germinates within 10 days. Zaria Nkpologwu, Awka, Owa and Udi accessions germinated between 11.00-11.50 days. In 2012 the data generated indicated that Agbani accession recorded the highest number of days to germination of which was significantly different from value obtained from Zaria and Owa 
accessions, Nkpologwu and Eke recorded the same value (13.25 days) of number of days to germination. The means for the two years data showed increased value in days to germination in 2012 for the castor accessions studied compared to their recorded values in 2011 year cropping.

TABLE 1: NUMBER OF DAYS TO GERMINATION FOR EACH OF THE CASTOR ACCESSIONS STUDIED

\begin{tabular}{cccc}
\multicolumn{4}{c}{ ACCESSIONS STUDIED } \\
\hline & & \multicolumn{2}{c}{ Days to germination } \\
\cline { 3 - 4 } S/N & Accessions & 2011 & 2012 \\
\cline { 3 - 4 } & & 11.25 & 15.25 \\
\hline 1 & Zaria & 12.25 & 13.25 \\
2 & Enugu & 10.00 & 11.75 \\
3 & Igboeze & 11.50 & 13.25 \\
4 & Nkpologwu & 11.00 & 12.75 \\
5 & Awka & 12.25 & 14.75 \\
6 & Agbani & 10.00 & 13.25 \\
7 & Eke & 11.50 & 11.00 \\
8 & Owa & 11.25 & 13.50 \\
9 & Udi & 11.22 & 13.19 \\
& Mean & 1.34 & 3.47 \\
\hline
\end{tabular}

B. Estimates of Phenotypic, Genotypic, Environmental and Genotype X Year Interaction Variation and Coefficient of Variation for Number of Days to Germination

The heritability estimates for number of days to germination were 35\% and 5\% for 2011 and 2012 respectively (Table 2). The phenotypic variance estimate were 1.29 and 5.97 for 2011 and 2012 respectively and 3.96 for genotype $\mathrm{x}$ year interaction while the genotypic variance estimates for number of days to germination in 2011 and 2012 were approximate 0.45 and 0.32 respectively and $74 \%$ for the genotype $x$ year interaction. The results presented in Table 2, also show that the environmental variance estimate for number of days to germination were 0.84 and 5.65 for 2011 and 2012 respectively and 3.19 for genotype x year interaction. The result equally indicated that the genotypic and phenotypic coefficient of variations for days to germination for 2011 and 2012 were $6 \%$ and $10 \%$ and 4 and $19 \%$ respectively.

TABLE 2: ESTIMATES OF PHENOTYPIC, GENOTYPIC, ENVIRONMENTAL AND GENOTYPE X YEAR INTERACTION VARIATION, PERCENTAGE BROAD SENSE HERITABILITY, PHENOTYPIC AND GENOTYPIC COEFFICIENT OF VARIATION FOR NUMBER OF DAYS TO GERMINATION

\begin{tabular}{|c|c|c|c|}
\hline \multirow{2}{*}{ Parameter } & \multicolumn{2}{|c|}{ Year } & \multirow{2}{*}{ GXY } \\
\hline & 2011 & 2012 & \\
\hline$\delta^{2} p h$ & 1.29 & 5.97 & 3.96 \\
\hline$\delta^{2} g$ & 0.45 & 0.32 & 0.74 \\
\hline$\delta^{2} e$ & 0.84 & 5.65 & 3.19 \\
\hline $\mathrm{H}^{2}(\mathrm{bc}) \%$ & $35 \%$ & $5 \%$ & \\
\hline PVC \% & $10 \%$ & $19 \%$ & \\
\hline GCV \% & $6 \%$ & $8 \%$ & \\
\hline
\end{tabular}

\section{Number of Days to 50\% Flowering for Each of the Castor Accessions}

The result of days to $50 \%$ flowering of castor accessions presented in Table 3, showed significant $(\mathrm{P}<0.05)$ difference among the castor accessions studied. The list and highest value for number of days to $50 \%$ flowering was recorded by Zaria (74.5 days) and Eke (101.0 days) accessions, while others show result variation of Awka (91.5 days) > Igboeze (89.5 days)> Udi (87.8 day) > Nkpologwu (85.5 days) > Enugu (84.5days) > Agbani (80.2 days) $>$ Owa (77.2 day) respectively in 2011 year.
In 2012 cropping year, there was an increase in the recorded value of number of days to $50 \%$ flowering by the entire castor accessions visa via their recorded value in 2011 year. The list value among all the accessions in 2012 was obtained from Zaria accession and the highest from Owa accessions.

TABLE 3: NUMBER OF DAYS TO 50\% FLOWERING FOR EACH OF THE CASTOR ACCESSIONS STUDIED

\begin{tabular}{clll}
\hline \multirow{2}{*}{ S/N } & \multirow{2}{*}{ Accessions } & \multicolumn{2}{c}{ Days to 50\% flowering } \\
\cline { 3 - 4 } & & 2011 & 2012 \\
\cline { 3 - 4 } 1 & Zaria & 74.5 & 81.00 \\
2 & Enugu & 84.5 & 124.5 \\
3 & Igboeze & 89.5 & 123.8 \\
4 & Nkpologwu & 85.5 & 137.5 \\
5 & Awka & 91.5 & 121.2 \\
6 & Agbani & 80.2 & 137.2 \\
7 & Eke & 101.0 & 139.2 \\
8 & Owa & 77.2 & 149.5 \\
9 & Udi & 87.8 & 142.8 \\
& Mean & 85.8 & 128.5 \\
& LSD 0.05 & 12.15 & 12.28 \\
\hline
\end{tabular}

D. Estimate of phenotype, genotype, environmental and genotype $x$ year interaction variation, percentage broad sense heritability, phenotypic and genotypic coefficient of variation for number of days to $50 \%$ flowering

The result presented in Table 4, showed that heritability estimates for number of days to $50 \%$ flowering were $40 \%$ and $85 \%$ in 2011 and 2012, respectively. The phenotypic variance estimate was 116.3 and 461.42 for 2011 and 2012 respectively and 344.77 for genotype $\mathrm{x}$ year interactions. The genotypic variance estimate for number of days to $50 \%$ flowering was 46.96 and 390.6 for 2011 and 2012 and 274.12 for genotype $\mathrm{x}$ year interaction, respectively. The genotype and phenotypic coefficient of variation for number of days to $50 \%$ flowering were $8 \%$ and $13 \%$ and $15 \%$ and $17 \%$ respectively for 2011 and 2012 .

TABLE 4: ESTIMATES OF PHENOTYPIC, GENOTYPIC, ENVIRONMENTAL AND GENOTYPE X YEAR INTERACTION VARIATION, PERCENTAGE BROAD SENSE HERITABILITY, PHENOTYPIC AND GENOTYPIC COEFFICIENT OF VARIATION FOR NUMBER OF DAYS TO GERMINATION 50\% FLOWERING

\begin{tabular}{|c|c|c|c|}
\hline \multirow{2}{*}{ Accessions } & \multicolumn{2}{|c|}{ Year } & \multirow{2}{*}{ GXY } \\
\hline & 2011 & 2012 & \\
\hline$\delta^{2} p h$ & 116.30 & 461.42 & 344.77 \\
\hline$\delta^{2} g$ & 46.96 & 390.6 & 274.12 \\
\hline$\delta^{2} e$ & 69.34 & 70.82 & 70.65 \\
\hline $\mathrm{H}^{2}(\mathrm{bc}) \%$ & $40 \%$ & $85 \%$ & \\
\hline PVC \% & $13 \%$ & $17 \%$ & \\
\hline GCV \% & $8 \%$ & $15 \%$ & \\
\hline
\end{tabular}

\section{E. Plant Height for Each of the Castor Accessions}

The plant height result for the nine (9) castor accession showed significant difference among the accessions studied (Table 5). The 2011 cropping season result showed the lowest $124.13 \mathrm{~cm}$ height of castor plant to be recorded by Zaria accessions, while the highest value of plant height $(162.78 \mathrm{~cm})$ was recorded by Owa accession. However, the plant height values of Nkpologwu $(139.23 \mathrm{~cm})$, Awka $(136.75 \mathrm{~cm})$, Enugu $(134.28 \mathrm{~cm})$ and Agbani $(134.15 \mathrm{~cm})$ accessions were statistically similar. The 2012 year showed a result variation of Owa $(156.7 \mathrm{~cm})>$ Zaria $(151.2 \mathrm{~cm})>$ Udi $(147.4 \mathrm{~cm})>$ Enugu $(138.7 \mathrm{~cm})>$ Eke $(130.0 \mathrm{~cm})>$ Igboeze $(127.5 \mathrm{~cm})>\operatorname{Nkpologwu}(123.9 \mathrm{~cm})>$ Awka $(122.4 \mathrm{~cm})>$ Agbani $(119.1 \mathrm{~cm})$ respectively. When the two years are compared, there was a decrease in plant 
height value in the second year (2012) except for Owa, Udi, Zaria, and Enugu accessions that showed increase in plant height. The 2011 plant height value with a range of $124.13 \mathrm{~cm}$ to $152.78 \mathrm{~cm}$ has a mean of $136.24 \mathrm{~cm}$, while 2012 with a range of $119.1 \mathrm{~cm}$ to $156.7 \mathrm{~cm}$ has a mean of $135.2 \mathrm{~cm}$.

TABLE 5: Plant HeIGHT FOR EACH OF THE CASTOR ACCESSIONS

\begin{tabular}{lccc}
\multicolumn{3}{c}{ STUDIED } \\
\cline { 3 - 4 } & & \multicolumn{2}{c}{ Plant height $(\mathrm{cm})$} \\
\cline { 3 - 4 } & Accessions & 2011 & 2012 \\
\cline { 3 - 4 } 1 & Zaria & 124.13 & 151.2 \\
2 & Enugu & 134.28 & 138.7 \\
3 & Igboeze & 131.88 & 127.5 \\
4 & Nkpologwu & 139.23 & 123.9 \\
5 & Awka & 136.75 & 122.4 \\
6 & Agbani & 134.15 & 119.1 \\
7 & Eke & 142.73 & 130.0 \\
8 & Owa & 152.78 & 156.7 \\
9 & Udi & 130.25 & 147.4 \\
& Mean & 136.24 & 135.2 \\
& LSD 0.05 & 7.09 & 22.95 \\
\hline
\end{tabular}

F. Estimates of Phenotypic, Genotype, Environmental and Genotype X Year Interaction Variation, Percentage Broad Sense Heritability, Phenotypic and Genotypic Coefficient of Variation for Mean Plant Height

The result presented in Table 6 showed that heritability estimates for plant were $72 \%$ and 34\% for 2011 and 2012 years respectively, while phenotypic variance estimates for the plant height indicated 84.52 for 2011 and 375.3 for 2012 and 233.83 for genotype $\mathrm{x}$ year interaction. The genotypic variance estimate for plant height were 60.92 and 4127.9 for 2011 and 2012 respectively and 105.72 for genotype $\mathrm{x}$ year interaction. The environmental variance estimate was 23.60 and 247.4 for 2011 and 2012 respectively and 551.0 for genotype $\mathrm{x}$ year interaction. The genotypic and phenotypic coefficient of variation for plant height was $8 \%$ and $22 \%$ for 2011 and $15 \%$ and $25 \%$ for 2012 respectively.

TABLE 6: ESTIMATES OF PHENOTYPIC, GENOTYPIC, ENVIRONMENTAL AND GENOTYPE X YEAR INTERACTION VARIATION, PERCENTAGE BROAD SENSE HERITABILITY, PHENOTYPIC AND GENOTYPIC COEFFICIENT OF

\begin{tabular}{cccc}
\multicolumn{4}{c}{ VARIATION FOR MEAN PLANT HEIGHT } \\
\hline Parameter & 2011 & 2012 & GXY \\
\hline$\delta^{2} p h$ & 84.52 & 375.3 & 233.83 \\
$\delta^{2} g$ & 60.92 & 412.9 & 105.73 \\
$\delta^{2} e$ & 23.60 & 247.4 & 551.0 \\
$\mathrm{H}^{2}(\mathrm{bc}) \%$ & $72 \%$ & $34 \%$ & \\
PVC \% & $22 \%$ & $25 \%$ & \\
GCV \% & $8 \%$ & $15 \%$ & \\
\hline
\end{tabular}

G. Length of Primary Raceme for Each of the Castor Accession

Zaria accession recorded the highest length of primary raceme of 30.60 which is significantly $(\mathrm{P}<0.05)$ different from all the accessions except the Igboeze accession that recorded 25.60 for length of primary raceme in 2011. The 2012 result showed Zaria accession to have the highest length of primary raceme of 18.88 this was closely followed by Igboeze (17.67), Awka (16.82), Nkpologwu (15.90), Eke (15.30), Udi (15.9) and Agbani (4.27), while the value recorded for Enugu (11.55) and Owa (11.55) accessions were statistically similar. The length for primary raceme of range $12.58-30.60$ in 2011 showed a mean of 20.22 and $11.55-18.88$ in 2012 with a mean of 15.22.
TABLE 7: LeNGTH OF PRIMARY RACEME FOR EACH OF THE CASTOR ACCESSIONS STUDIED

\begin{tabular}{|c|c|c|c|}
\hline \multirow{3}{*}{$\mathrm{S} / \mathrm{N}$} & \multirow{3}{*}{ Accessions } & \multicolumn{2}{|c|}{ Lenght of primany raceme $(\mathrm{cm})$} \\
\hline & & \multicolumn{2}{|c|}{ Year } \\
\hline & & 2011 & 2012 \\
\hline 1 & Zaria & 30.60 & 18.88 \\
\hline 2 & Enugu & 20.55 & 11.55 \\
\hline 3 & Igboeze & 25.60 & 17.67 \\
\hline 4 & Nkpologwu & 18.80 & 15.90 \\
\hline 5 & Awka & 20.93 & 16.82 \\
\hline 6 & Agbani & 12.58 & 14.27 \\
\hline 7 & Eke & 14.45 & 15.30 \\
\hline 8 & Owa & 18.58 & 11.55 \\
\hline \multirow[t]{3}{*}{9} & Udi & 20.83 & 15.00 \\
\hline & Mean & 20.32 & 15.22 \\
\hline & LSD 0.05 & 7.09 & 22.95 \\
\hline
\end{tabular}

H. Estimates of Phenotypic, Genotypic, Environmental and Genotype X Year Interaction Variation, Percentage Broad Sense Heritability, Phenotypic and Genotypic Coefficient of Variation for Length of Primary Raceme

The result presented in Table 8 showed that heritability estimates for length of primary raceme were $54 \%$ and 75 for 2011 and 2012, respectively. The phenotypic variance estimates were 29.11 and 20.58 for 2011 and 2012, respectively and 38.194 for genotype $\mathrm{x}$ year interaction. The genotypic variance estimate for length of primary raceme was 15.8 and 1.52 for 2011 and 2012, respectively, while the genotype $\mathrm{x}$ year interaction was $21.18 \%$. The environmental variance estimates were 13.81 and 19.06 for 2011 and 2012, respectively and $17.7 \%$ for genotype x year interaction while genotypic and phenotypic coefficient of variation for length of primary raceme for 2011 and 2012 were $20 \%$ and $27 \%$ and $8 \%$ and $30 \%$, respectively.

TABLE 8: ESTIMATES OF PHENOTYPIC, GENOTYPIC, ENVIRONMENTAL AND GENOTYPE X YEAR INTERACTION VARIATION, PERCENTAGE BROAD SENSE HERITABILITY, PHENOTYPIC AND GENOTYPIC COEFFICIENT OF VARIATION FOR LENGTH OF PRIMARY RACEME.

\begin{tabular}{cccc}
\hline \multirow{2}{*}{ Parameter } & \multicolumn{3}{c}{ Year } \\
\cline { 2 - 4 } & 2011 & 2012 & $\mathrm{GXY}$ \\
\hline$\delta^{2} p h$ & 29.11 & 20.58 & 38.194 \\
$\delta^{2} g$ & 15.8 & 1.52 & 21.18 \\
$\delta^{2} e$ & 13.31 & 19.06 & $17.7 \%$ \\
$\mathrm{H}^{2}(\mathrm{bc}) \%$ & $54 \%$ & $7 \%$ & \\
PVC \% & $27 \%$ & $30 \%$ & \\
GCV \% & $20 \%$ & $8 \%$ & \\
\hline
\end{tabular}

I. Length of Pistillate Region for Each of the Castor Accession

The result of length of pistillate region for the nine castor accession presented in Table 9 showed that the highest $(20.98 \mathrm{~cm})$ value of the length of pistillate region was obtained from Zaria accession in 2011 year. This value was significantly $(\mathrm{P}<0.05)$ different from the values obtained from Nkpologwu $(13.30 \mathrm{~cm})$; Enugu $(13.30 \mathrm{~cm})$; Udi $(13.03 \mathrm{~cm})$ Eke $(11.15 \mathrm{~cm})$; Owa $(10.30 \mathrm{~cm})$ and Agbani $(8.0 \mathrm{~cm})$ accessions. The length of pistillate region of Zaria $(20.98 \mathrm{~cm})$, Igboeze $(20.10 \mathrm{~cm})$ and Awka $(17.0 \mathrm{~cm})$ accessions were statistically similar, while Enugu $(13.30 \mathrm{~cm})$ and Nkpologwu gave the same value for length of pistillate region. The 2012 year result in Table 9 indicated that the highest value $(14.00 \mathrm{~cm})$ and lowest value $(8.20 \mathrm{~cm})$ for the length of pistillate region were obtained from Nkpologwu and Agbani accessions. When the two years (2011 and 2012) are compared, there was decrease in the length of pistillate region values recorded in each castor accessions in 2012. In 2011, the mean for the length of 
pistillate region is $14.16 \mathrm{~cm}$ with the range of $8.0-20.98 \mathrm{~cm}$, while in 2012 the mean was $10.91 \mathrm{~cm}$ with the range of $8.20-14.00 \mathrm{~cm}$.

TABLE 9: LENGTH OF PISTILLATE REGION FOR EACH OF THE CASTOR ACCESSIONS STUDIED

\begin{tabular}{cccc}
\hline \multirow{2}{*}{ S/N } & \multirow{2}{*}{ Accessions } & \multicolumn{2}{c}{ Lenght of pistilillate region $(\mathrm{cm})$} \\
\cline { 3 - 4 } & & 2011 & 2012 \\
\cline { 3 - 4 } & Zaria & 20.98 & 12.78 \\
1 & Enugu & 13.30 & 11.40 \\
2 & Igboeze & 20.10 & 10.60 \\
3 & Nkpologwu & 13.30 & 14.00 \\
4 & Awka & 17.0 & 11.17 \\
5 & Agbani & 8.0 & 8.20 \\
6 & Eke & 11.15 & 9.03 \\
7 & Owa & 10.30 & 9.0 \\
8 & Udi & 13.03 & 11.50 \\
9 & Mean & 14.16 & 10.91 \\
& LSD 0.05 & 5.32 & 3.85 \\
\hline
\end{tabular}

J.Estimate of Phenotypic, Genotypic, Environmental and Genotype X Year Interaction Variation, Percentage Broad Sense Heritability, Phenotypic and Genotypic Coefficient of Variation for mean Length of Pistillate Region

The phenotypic variance estimates for 2011 and 2012 planting years presented in Table 10 were 43.12 and 8.77 respectively and 23.38 for genotypic x year interaction. The genotypic variance estimates for length of pistillate region were 24.63 and 1.82 for 2011 and 2012 respectively, while the genotype $\mathrm{x}$ year interaction is 13.76 . The heritability estimates were $57 \%$ and $20 \%$ for 2011 and 2012, respectively; while the environmental variance estimate for length of pistillate region were 18.49 and 6.951 for 2011 and 2012, respectively and 9.62 for genotype $\mathrm{x}$ year interaction. The result presented in Table 10 equally indicated that the genotypic and phenotypic coefficient of variation for length of pistillate region for 2011 and 2012 were $35 \%$ and $47 \%$ and $12 \%$ and $27 \%$, respectively.

TABLE 10: ESTIMATES OF PHENOTYPIC, GENOTYPIC, ENVIRONMENTAL AND GENOTYPE X YEAR INTERACTION VARIATION, PERCENTAGE BROAD SENSE HERITABILITY, PHENOTYPIC AND GENOTYPIC COEFFICIENT OF VARIATION FOR MEAN LENGTH OF PISTILLATE REGION

\begin{tabular}{|c|c|c|c|}
\hline \multirow{2}{*}{ Parameter } & \multicolumn{2}{|c|}{ Year } & \multirow{2}{*}{ GXY } \\
\hline & 2011 & 2012 & \\
\hline$\delta^{2} p h$ & 43.12 & 8.77 & 23.38 \\
\hline$\delta^{2} g$ & 24.63 & 1.82 & 13.76 \\
\hline$\delta^{2} e$ & 11.49 & 6.951 & 9.62 \\
\hline $\mathrm{H}^{2}(\mathrm{bc}) \%$ & $57 \%$ & $20 \%$ & \\
\hline PVC \% & $46 \%$ & $27 \%$ & \\
\hline GCV \% & $35 \%$ & $12 \%$ & \\
\hline
\end{tabular}

K. Length of Staminate Region for Each of Castor Accessions

The length of staminate region result presented in Table 11 showed significant $(\mathrm{P}<0.05)$ different among the castor accessions studied. In 2011 the result indicated that Zaria $(8.00 \mathrm{~cm})$, Owa $(8.01 \mathrm{~cm})$, Udi $(8.02 \mathrm{~cm})$, Igboeze $(6.75 \mathrm{~cm})$ accessions are statistically similar. In like manner, length of staminate region for Enugu $(4.47 \mathrm{~cm})$, Nkpologwu (4.25 cm), Awka (4.75 cm), Agbani $(4.57 \mathrm{~cm})$ and Eke $(4.80 \mathrm{~cm})$ accessions show statistically similar values. In 2012, the length of staminate region showed increase in value in all the castor accessions when compared with the 2011 result except for Owa accession that showed slight decrease in value in 2012 year. The lowest $(7.50 \mathrm{~cm})$ and highest (11.75) for the length of staminate region for 2012 was obtained from Owa and Udi accessions respectively in 2011 the mean length of staminate region is $5.96 \mathrm{~cm}$ with a range of 4.25 to $8.02 \mathrm{~cm}$ while in 2012 the mean length of staminate region was 9.24 with a range of $7.50-1175 \mathrm{~cm}$

TABLE 11: LENGTH OF STAMINATE REGION FOR EACH OF THE CASTOR ACCESSIONS STUDIED

\begin{tabular}{cccc}
\hline & & \multicolumn{2}{c}{ Lenght of staminate $(\mathrm{cm})$} \\
\cline { 3 - 4 } S/N & Accessions & 2011 & Year \\
\cline { 3 - 4 } & & 8.00 & 9.60 \\
\hline 1 & Zaria & 4.47 & 8.30 \\
2 & Enugu & 6.75 & 8.12 \\
3 & Igboeze & 4.25 & 8.72 \\
4 & Nkpologwu & 4.75 & 10.50 \\
5 & Awka & 4.57 & 9.42 \\
6 & Agbani & 4.80 & 7.80 \\
7 & Eke & 8.01 & 7.50 \\
8 & Owa & 8.02 & 11.75 \\
9 & Udi & 5.96 & 9.24 \\
& Mean & 2.43 & 3.36 \\
\hline
\end{tabular}

L. Estimate of Phenotypic, Genotypic, Environmental and Genotype X Year Interaction Variation Percentage Broad Sense Heritability, Phenotypic and Genotypic Coefficient of Variation for Length of Staminate Region

The environmental variation estimates for length of staminate region for 2011 and 2012 were 2.76 and 5.31 respectively, while the genotype $\mathrm{x}$ year interaction is 3.84 . The genotypic variance estimates recorded for 2011 and 2012 were 2.22 and 0.41 respectively and 1.67 for genotype $\mathrm{x}$ year interaction while the phenotypic variance estimates for length of staminate region were 4.98 and 5.72 for 2011 and 2012, respectively and 5.50 for genotype $x$ year interaction. The heritability estimate for length of staminate region were $45 \%$ and $7 \%$ in 2011 and 2012, respectively, while genotypic and phenotypic coefficient of variation for length of staminate region for 2011 and 2012 were $25 \%$ and $37 \%$ and $7 \%$ and $26 \%$, respectively.

TABLE 12: ESTIMATES OF PHENOTYPIC, GENOTYPIC, ENVIRONMENTAL AND GENOTYPE X YEAR INTERACTION VARIATION, PERCENTAGE BROAD SENSE HERITABILITY, PHENOTYPIC AND GENOTYPIC COEFFICIENT OF VARIATION FOR LENGTH OF STAMINATE REGION

\begin{tabular}{|c|c|c|c|}
\hline \multirow{2}{*}{ Parameter } & \multicolumn{2}{|c|}{ Year } & \multirow{2}{*}{ GXY } \\
\hline & 2011 & 2012 & \\
\hline$\delta^{2} p h$ & 4.98 & 5.72 & 5.50 \\
\hline$\delta^{2} g$ & 2.22 & 0.41 & 1.67 \\
\hline$\delta^{2} e$ & 2.76 & 5.31 & 3.84 \\
\hline $\mathrm{H}^{2}(\mathrm{bc}) \%$ & $45 \%$ & $7 \%$ & \\
\hline PVC \% & $37 \%$ & $26 \%$ & \\
\hline GCV \% & $25 \%$ & $7 \%$ & \\
\hline
\end{tabular}

M. Number of Nodes to Primary Raceme for Each of the Castor Accession

The number of nodes to primary raceme of the nine castor accessions presented in Table 13 showed significant $(\mathrm{P}<0.05)$ difference among the accessions studied. In 2011 the result indicated that Igboeze accession recorded the highest (19.25) number of nodes to primary raceme of which is significantly different from Zaria (12.50) and Agbani (16.25) accessions, while the number of nodes to primary raceme obtained from Igboeze (19.25), Enugu (19.00), Nkpologwu (18.25), Awka (19.00), Eke (18.25), Owa (18.00) and Udi (17.75) were statistically similar; Enugu accession and Awka accession recorded the same number of nodes to primary raceme of 19.00 as well as 
Nkpologwu and Eke accessions that recorded the same value (18.25) for the number of nodes to primary raceme. In 2012 the number of nodes to primary raceme result showed that the highest value (20.25) for the parameter was obtained from Owa accession. Zaria and Nkpologwu accession recorded the same value (16.00) of which is the lowest number of nodes to the primary raceme compared to the other castor accessions studied. Also the number of nodes to primary raceme of Igboeze and Owa accessions is the same (17.50). With the range of $12.50-19.25$ the mean number of nodes to primary raceme was 17.58 in 2011 , while 2012 showed a mean of 17.78 of number of nodes to primary raceme with a range of 16.0-20.25. By the virtue of their means the number of nodes to primary raceme of the accessions for the 2011 and 2012 did not differ much.

TABLE 13: NUMBER OF NODES TO PRIMARY RACEME FOR EACH OF THE

\begin{tabular}{cccc}
\multicolumn{3}{c}{ CASTOR ACCESSIONS STUDIED } \\
\cline { 3 - 4 } S/N & \multirow{2}{*}{ Accessions } & 2011 & 2012 \\
\cline { 3 - 4 } 1 & Zaria & 12.50 & 16.00 \\
2 & Enugu & 19.00 & 16.25 \\
3 & Igboeze & 19.25 & 17.50 \\
4 & Nkpologwu & 18.25 & 16.00 \\
5 & Awka & 19.00 & 17.75 \\
6 & Agbani & 16.25 & 19.75 \\
7 & Eke & 18.25 & 17.50 \\
8 & Owa & 18.00 & 20.25 \\
9 & Udi & 17.75 & 19.50 \\
& Mean & 17.58 & 17.78 \\
& LSD 0.05 & 1.79 & 3.30 \\
\hline
\end{tabular}

N. Estimates of Phenotype, Genotype, Environmental and Genotype X Year Interaction Variation, Percentage Broad Sense Heritability, Phenotypic and Phenotypic Coefficient of Variation for Number of Nodes

The phenotypic variances estimates for the number of nodes to primary raceme were 5.57 and 6.34 for 2011 and 2012 respectively and 6.37 for genotype x year interaction (Table 14). Heritability estimates for number of nodes to primary raceme for 2011 and 2012 were $73 \%$ and $19 \%$ respectively. The genotypic variance estimates for number of nodes to primary raceme in 2011 and 2012 were 4.06 and 1.2 respectively and 3.23 for genotype $\mathrm{x}$ year interaction. The results also presented in Table 14 show that the environmental variance estimate for number of nodes to primary raceme were 1.51 and 5.11 for 2011 and 2012 respectively and 3.13 for genotype $x$ year interaction. The genotypic and phenotypic coefficient of variation for number of nodes to the primary raceme for 2011 and 2012 were $11 \%$ and $6 \%$ and $13 \%$ and $14 \%$, respectively.

TABLE 14: ESTIMATES OF PHENOTYPIC, GENOTYPIC, ENVIRONMENTAL AND GENOTYPE X YEAR INTERACTION VARIATION, PERCENTAGE BROAD SENSE HERITABILITY, PHENOTYPIC AND GENOTYPIC COEFFICIENT OF VARIATION FOR NUMBER OF NODE

\begin{tabular}{cccc}
\multicolumn{3}{c}{ VARIATION FOR NUMBER OF NODE } \\
\cline { 2 - 3 } Parameter & 2011 & \multirow{2}{*}{ GXY } \\
\hline$\delta^{2} p h$ & 5.57 & 6.34 & 6.37 \\
$\delta^{2} g$ & 4.06 & 1.2 & 3.23 \\
$\delta^{2} e$ & 1.51 & 5.11 & 3.13 \\
$\mathrm{H}^{2}(\mathrm{bc}) \%$ & $73 \%$ & $19 \%$ & \\
PVC \% & $13 \%$ & $14 \%$ & \\
GCV \% & $11 \%$ & $6 \%$ & \\
\hline
\end{tabular}

\section{O. Number of Leaves for Each of the Castor Accession}

The result of the number of leaves of castor accessions presented in Table 15 showed significant difference among the castor accessions studied. The 2011 result indicated that Udi (23.25), Owa (23.25) and Agbani (23.25) accessions recorded the same number of leaves, while the lowest value (20.0) of number of leaves was obtained from Enugu accession. In 2012 the number of leaves obtained from Owa and Zaria accessions showed the lowest (20.50) and highest (26.75) respectively compared to the other castor accessions studied. The mean number of leaves was 22.42 with the range of 20.0 to 23.75 in 2011 and in 2012 the mean number of leaves was 23.25 with the range of 20.50 to 26.75 .

TABLE 15: NUMBER OF LEAVES FOR EACH OF THE CASTOR ACCESSIONS STUDIED

\begin{tabular}{cccc}
\hline \multirow{2}{*}{ S/N } & \multirow{2}{*}{ Accessions } & \multicolumn{2}{c}{ Number of Leaves } \\
\cline { 3 - 4 } & & 2011 & 2012 \\
\hline 1 & Zaria & 21.03 & 20.50 \\
2 & Enugu & 20.00 & 21.75 \\
3 & Igboeze & 20.75 & 21.50 \\
4 & Nkpologwu & 23.00 & 21.75 \\
5 & Awka & 23.50 & 22.25 \\
6 & Agbani & 23.25 & 25.00 \\
7 & Eke & 23.75 & 24.00 \\
8 & Owa & 23.25 & 26.75 \\
9 & Udi & 23.25 & 23.75 \\
& Mean & 22.42 & 23.25 \\
& LSD 0.05 & 1.33 & 1.15 \\
\hline
\end{tabular}

P. Estimate of Phenotypic, Environmental and Genotype $X$ Year Interaction Variation Percentage Broad Sense Heritability, Phenotypic and Genotypic Coefficient of Variation for Number of Leaves

The heritability estimates for number of leaves in 2011 and 2012 were $72 \%$ and $34 \%$ respectively (Table 16). The phenotypic variance estimates for number of leaves were 84.52 and 375.3 in 2011 and 2012 respectively while 233.83 was recorded for genotype $\mathrm{x}$ year interaction. The genotypic estimates were 60.92 and 4127.9 for 2011 and 2012 respectively and 105.73 for genotype $x$ year interaction. The environmental variance estimates were 23.60 and 247.4 for 2011 and 2012 and 551.0 for genotype $\mathrm{x}$ year interaction. The results presented in Table 16 also indicated that the genotypic and phenotypic coefficient of variation for number of leaves were $22 \%$ and $25 \%$ and $32 \%$ and 55\% for 2011 and 2012, respectively.

TABLE 16: ESTIMATES OF PHENOTYPIC, GENOTYPIC, ENVIRONMENTAL AND GENOTYPE X YEAR INTERACTION VARIATION, PERCENTAGE BROAD SENSE HERITABILITY, PHENOTYPIC AND GENOTYPIC COEFFICIENT OF VARIATION FOR NUMBER OF LEAVES

\begin{tabular}{|c|c|c|c|}
\hline \multirow{2}{*}{ Parameter } & \multicolumn{2}{|c|}{ Year } & \multirow{2}{*}{ GXY } \\
\hline & 2011 & 2012 & \\
\hline$\delta^{2} p h$ & 84.52 & 375.3 & 233.83 \\
\hline$\delta^{2} g$ & 60.92 & 4127.9 & 105.73 \\
\hline$\delta^{2} e$ & 23.60 & 247.4 & 551.0 \\
\hline $\mathrm{H}^{2}(\mathrm{bc}) \%$ & $72 \%$ & $34 \%$ & \\
\hline PVC \% & $25 \%$ & $55 \%$ & \\
\hline GCV \% & $22 \%$ & $25 \%$ & \\
\hline
\end{tabular}




\section{DISCUSSION}

The observed significant variations in agronomic parameters assessed among the castor accessions studied is a true indication of the different among the genotype under study and the existence of possible genetic divergence in castor bean plant. The high level of variability in the population suggests that heterosis could be utilized to produce superior hybrids, which can further be used in breeding programmes to develop superior accessions. Furthermore, the significant and comparably large genotypic and phenotypic variance among the accessions for all traits except number of days to germination, number of nodes, and length of staminate region implies that there would be adequate gains in selecting these characters. The estimates of environmental variance, however, were larger than genotypic variances in characters like number of days to germination and length of staminate region indicating that these characters were to a larger extent influenced by the environment unlike the other traits. Phenotypic coefficient of variance (PVC) was higher than genotypic coefficient of variance (GCV) for all the character studied indicating the influence of environment towards the total variance. Higher magnitudes of GCV and PVC for days to 50\% flowering in 2011 (116.30 and 46.90), in 2012 (461.42 and 390.6), length of pistillate region in 2011 (43.12 and $24.63)$, length of primary raceme 29.58 and 15.8 in plant height in $201184.52 \mathrm{~cm}$ and 60.92 and in 2012 (375.2 and 4127.9) indicated the presence of high amount of variability. Nonetheless, low values were obtained per number of days to germination, number of nodes and length of staminate region. Similar results were obtained by Golakia et al. [15], Patel et al. [16] and Ramesh et al. [17]. The presence of genotype $\mathrm{x}$ year environment (GXE) interaction justifies the need for broad based testing in different or years the degree of performance can help predict variability expected among farms. Exploiting GXE would enhance specific genotype recommendation for specific area of adaptation. Phonological behaviour of the different accessions was reflective of the environment. For example, the number of days to $50 \%$ flowering was statistically similar for all the accessions except genotype 8 (Owa accession) in 2011 and for accessions 2(Enugu), 3(Igboeze) and 6 (Agbani) in 2012.

Phonological traits are strongly influenced by weather especially lack of or excess soil moisture. For the present study, moisture rather than temperature was a major determination of caster performances. There were variations recorded in germination time. Some of the varieties that germinated early in 2011 took more days to germinate in 2012. Water softens the seed coat and made it easier for mineral materials and oxygen to move from one part of the seed to another. In seeds germination begins after moisture has been absorbed by radical emerging through the seed coats further development varies partly depending on whether food reserved are stored in an endosperm or cotyledons. The performance of the castor accessions for the two years planting season was observed to be consistent. Genotype 1 (Zaria) was found to be the first to flower and gave the overall best performance in all the agro economic attributes considered in this study.

\section{CONCLUSION}

The success of most crop improvement programmes largely depends upon the genetic variability and the heritability of desirable traits. The magnitude and type of genetic variability help the breeder to determine the selection criteria and breeding schemes to be used for improvement purposes. The existence of genotype $\mathrm{x}$ environment interaction means that recommendation could not be solely based on mean performance. Inconsistent performance of accessions indicated the existence of genotype $\mathrm{x}$ environmental interaction. The present study showed that there are rank charges of accessions for all the traits evaluated thus causes complication in accessions recommendation. The accessions that will eventually be recommended should have majority of those characters that will enhance productivity.

\section{REFERENCE}

[1] Nweke, I. A. (2019a). Effect of tillage practices and wood ash on soil properties and yield of castor (ricinus communis) on an ultisol in Abakaliki south east Nigeria A PhD Thesis submitted to the Department of Soil Science and Environmental Management, Ebonyi State University, Abakaliki, Nigeria Pp 86-88.

[2] Moreno-Gonzalez J. and Cubero, J.I. (1993). Selection strategies and choice of breeding method in plant breeding principles and prospects edited by M. D Hayward, N. O. Bosemark and I. Romagosa Chapman and Hall London; Pp 281-313.

[3] Dingkuhu, M. Schmer, H.F, Data, S.K. Dorffing and Javellana, C. (1991) Relationship between ripening phase productivity and crop production, canopy photosynthesis and senescence in transplanted and direct seeded lowland rice, Field Crop Res 26:327-345.

[4] Wada, G. and Cruz, P.S. (1989). Varietal differences on nitrogen response of rice plant with special reference to growth duration, J. Crop Sci. 732-739.

[5] Becker. H. C. and Leon, J. (1988). Stability analysis of in plant breeding; Plant Breeding 101:1-23.

[6] Baiyeri, K.P. (1998). Evaluation of growth, yield and yield components of 36 musa accessions under four different environments A PhD Thesis submitted to the Department of Crop Science, University of Nigeria, Nsukka Pp32.

[7] Obi, I.U. (1990). Crop improvement in agricultural development In: The challenges of Agriculture in National Development A production of the Faculty of Agriculture University of Nigeria, Nsukka; edited by A. I. Ikeme Optimal Computer Solution Ltd Enugu Pp-185.

[8] Kang, M.S.C. and Pharm., H. N. (1991). Simultaneous selection for high yield and stable crop accessions Agronomy 183:161-165.

[9] Nweke, I A (2019b). In support of massive cultivation of castor oil bean (Ricinus communis L) plant in Nigeria soils -A Review J. Agriculture and Agribusiness 4 (1): 19 - 29.

[10] Burton GW (1962). Quantitative Inheritance in grasses In: Proceedings of the Sixth International grassland Congress 1: 277 283.

[11] Johnson, H. W., Robinson, H. F., Comstock, R. F. (1995). Estimates of genetic and environmental variability in soybeans. Agronomy J. 47: $310-318$.

[12] Burton, G. W. and Devane, E. H., (1953). Estimating heritability in tall fescue (Festuca arundiaceae) from replicated colonial material. Agron J., 45: 478-481.

[13] Genstat (2005). Gensat 3.0 release 4.23DE. Discovery Edition 3, lawes Agricultural Trust, Rothams Experimental Station UK.

[14] Obi, I. U. (2002). Statistical method of detecting differences between treatment means for field and laboratory experiments AP Publishers Co. Ltd 117pp.

[15] Golakia PR, Kavani RH, Monpara BA. (2007). Genetic variation and trait relationship in castor National Journal of Plant Improvement 9(1): 60-62.

[16] Patel JR, Saiyed MP, Patel CG, Bhatt RK, Bhatt JP. (2010). Genetic variability and correlation studies in castor (Ricinus communis L.), Int. J Agric. Sci. (6(1):129-131.

[17] Ramesh M, Lavanya C, Brahmeshwar Rao MV. (2012). Genetic divergence in some indigenous and exotic germplasm lines of castor 
(Ricinus communis L.) under rainfed conditions. Indian Journal of Dry-land Agricultural Research and Development 27(2):79- 83. 